\title{
Metastatic Ewing's Sarcoma in Mandible: A Rarity
}

\author{
${ }^{I}$ Sachin Makne Mds, Assistant professor Pediatric and Preventive Dentistry, Government \\ Dental College, Aurangabad \\ ${ }^{2}$ Neha Bansal Mds, Oral Medicine And Radiology \\ ${ }^{3}$ Jaya Karamchandani Mds Oral and Maxillofacial Surgery \\ ${ }^{4}$ Shrikant Vanjari Mds Oral and Maxillofacial Surgery \\ ${ }^{5}$ Jayshri Wagatkar, Bds, Senior Resident, Department Of Periodontology, Government \\ Dental College, Aurangabad \\ Avinash Kolapkar Bds PGDHSM, Government \\ Dental College, Aurangabad \\ Kanchan shah Mds,Associate professor Oral and maxillofacial surgery, Government \\ Dental College, Aurangabad Department(S) And Institution(S):
}

\begin{abstract}
Ewing's sarcoma, a malignant tumor, rarely occurs in children younger than 12 years of age. Although it may appear in any bone, it is more common in the axial skeleton, rarely involving the jaws (1 to $2 \%$ incidence, mostly in the mandible). The most common symptoms are pain and swelling in the affected area. History of trauma often is reported. We report a rare case of metastatic Ewing's Sarcoma in posterior mandible of a 10 year old female patient.
\end{abstract}

Metastatic Ewing's sarcoma in mandible: A rarity

\section{Introduction}

James Ewing was the first to describe Ewing's sarcoma, which was named after him in 1921. Ewing's sarcoma (ES) is a rare malignant small round cell tumour that primarily affects the skeletal system ${ }^{1}$. It accounts for 4 to $10 \%$ of all types of bone cancer, with long bones and pelvis being the most common locations ${ }^{1,2} .90 \%$ occur in the first three decades of life and males are more often affected than females (male: female $=3: 2$ ) ${ }^{3,4} \mathrm{At}$ initial diagnosis, approximately $25 \%$ of patients with Ewing's Sarcoma present with clinically detectable metastases. ${ }^{5}$ Mandible is a rare site for metastases to occur and clinical symptoms such as swelling, pain and sensory disturbances are rather unspecific and can sometimes be misleading.

We report a rare case of metastatic Ewing's Sarcoma in posterior mandible of a 10 year old female patient.

\section{Case Report}

A 10 year old female patient reported with complains of swelling and numbness in right lower region of jaws since 4 days. She had been diagnosed with Ewing's Sarcoma affecting right lower extremity at the age of 5 years and was treated for the same.

A gross facial asymmetry with a well-circumscribed swelling measuring $5 \times 3 \mathrm{~cm}$ was present on the right posterior mandible (Fig. 1). On palpation, swelling was tender, bony hard in consistency, non-pulsatile and non-compressible with no evidence of secondary changes. Intraorally, swelling and obliteration of right mandibular vestibule was noted, extending from the region of right lower first premolar to retromolar area (Fig.2). The edges were indurated laterally with positive fluctuancy posteriorly. First molar was mobile. Hypoaesthesia of right lower lip was evident. Considering the patient's history and clinical observations, a malignant tumour of mandible was suspected, possibly metastatic tumour or lytic type of osteosarcoma or plasmacytoma. Patient was subjected to CBCT scan, hematologic and biochemical investigations, incisional biopsy along with removal of mobile tooth. CBCT (Fig.3) showed an expansive permeative lesion with ill defined borders, loss of lamina dura around first molar, loss of tooth bud cortication of second molar and loss of cortication of IAN canal. Lingual cortical plate was discontinuous. Hematological and biochemical parameters were within normal limits. Incisional biopsy confirmed Ewing's Sarcoma. Histologically (Fig.4), the hematoxylin and eosin and the periodic acid-Schiff stains showed a tumor infiltrate within the hematopoietic marrow, involving the adjacent soft tissue. Sheets and clusters of uniform, small round tumor cells with clear to faintly eosinophilic cytoplasm and relatively uniform finely stippled nuclear chromatin were seen. Occasional small nucleoli and tumor cell mitoses were found. The surrounding soft tissue was determined to be primarily loose fibroconnective tissue, with occasional areas of reactive new bone formation. Unfortunately, the patient passed away. 


\section{Discussion}

Ewing sarcomas are malignant small, round, blue cell tumours that primarily arise in bone and soft tissues with limited neuroepithelial differentiation. ${ }^{6}$ It accounts for 4 to10\% of all types of bone cancer, with nearly $50 \%$ of reported cases involving the femur and pelvis. ${ }^{2}$ It affects children and young adults, as also seen in our case. It has predilection for whites, with blacks and Asians being less frequently affected. ${ }^{3}$ Unlike our case, it affects males more than females. Only $2-7 \%$ of cases involve the maxillofacial region, usually involving the mandibular ramus, and few reported cases have involved maxilla. ${ }^{3}$ Approximately $90 \%$ of reported cases involving mandible have been primary lesions, and only $10 \%$ have been, similar to our case, metastases. Swelling, pain, paresthesia and loose teeth are frequent symptoms. ${ }^{7}$ Our patient presented with swelling, hypoesthesia and loose tooth of four days duration. As previously reported, development of ES lesion is often preceded by trauma, ${ }^{8}$ but no history of trauma was given by our patient.

Radiographically, it is a destructive expansile lesion which may produce laminated periosteal reaction. ${ }^{7}$ The 'sunray' appearance, is a common finding, ${ }^{9}$ but was not seen in the present case. An osteolytic radiolucent area area with cortical destruction was seen. Apart from metastatic carcinoma, other lesions that may present with the same pattern are osteogenic sarcoma, neuroblastoma, lymphosarcoma, histiocytosis $\mathrm{X}$ and osteomyelitis. Some findings such as the presence of a large soft tissue mass and the age of the patient, can facilitate differentiation between ES and these lesions. ${ }^{8}$ With respect to teeth, our case showed most of the reported features of loss of lamina dura, root resorption, displacement and more commonly destruction of unerupted tooth follicles. ${ }^{9}$

Histopathologically, this tumor must be differentiated from other small, round cell tumors, including small cell osteosarcoma and malignant neoplasms like mesenchymal chondrosarcoma. The prognosis of Ewing's sarcoma is poor, which is due to multiple metastases that occurs most commonly to the bone, lung, lymph node, and liver, and unlike our case, may present within a few months after the onset of the tumour. This case also presented with metastasis to mandible and had poor prognosis. Recently, some reports of early and prompt diagnosis with combined surgery, radiation, and chemotherapy protocols have raised the five-year survival rate of patients with Ewing's sarcoma from $16 \%$ to $74 \%$.

\section{Conclusion}

This case report highlights the fact that jaw metastases, albeit not a common characteristic of ES, should be suspected despite the post treatment status of ES. Imaging plays an important role in diagnosis and deciding on the therapeutic approach.

\section{References}

[1]. Vikas PB, Ahmed MBR, Bastian TS, David TP. Ewing`s sarcoma of the maxilla. Indian J Dent Res 2008;19:66-69.

[2]. Infante-Cossio P, Gutierrez-Perez JL, Garcia-Perla A, Noguer-Mediavilla M, Gavilan-Carrasco F. Primary Ewing's sarcoma of the maxilla and zygoma: report of a case. J Oral Maxillofac Surg 2005;63:1539-1542.

[3]. Talesh KT, Motamedi MHK, Jeihounian M. Ewing's sarcoma of the mandibular condyle: Report of a case. J Oral Maxillofac Surg. 2003;61:1216-1219

[4]. Ushigome S, Machinami R, Sorensen PH. Ewing sarcoma/Primitive neuroectodermal tumour (PNET) In: Fletcher CDM, Unni KK, Mertens F, editor. World Health Organization Classification of Tumours: Pathology and Genetics, Tumours of Soft Tissue and Bone. IARC Press, Lyon; 2002. pp. 298-300.

[5]. Bernstein M, Kovar H, Paulussen M, Randaal RL, Schuck A, Teot LA, Juergens H. Ewing's sarcoma family of tumours: current management. Oncologist 2006;11:503-19.

[6]. Tsokos M, Alaggio D, Dehner LP, Dickman PS. Ewing sarcoma/peripheral primitive neuroectodermal tumour and related tumours.. Pediatr Dev Pathol 2012;15:108-26.

[7]. Arafat A, Ellis GL, Adrian JC. Ewing's sarcoma of the jaws. Oral Surg Oral Med Oral Pathol 1983;55:589-96.

[8]. Singh JP, Garg L, Shrimali R, Gupta V. Radiological appearance of the mandible. Indian J Radiol Imaging. 2003;13:23-5.

[9]. Wood RE, Nortje C, Hesseling P, Grotepass F. Ewing's tumour of the jaw. Oral Surg Oral Med Oral Pathol 1990;69:120-27.

[10]. Hustu HO, Holton C, James D Jr, Pinkel D. Treatment of Ewing's sarcoma with concurrent radiotherapy and chemotherapy. J Pediatr 1968;73:249-51.

Figures

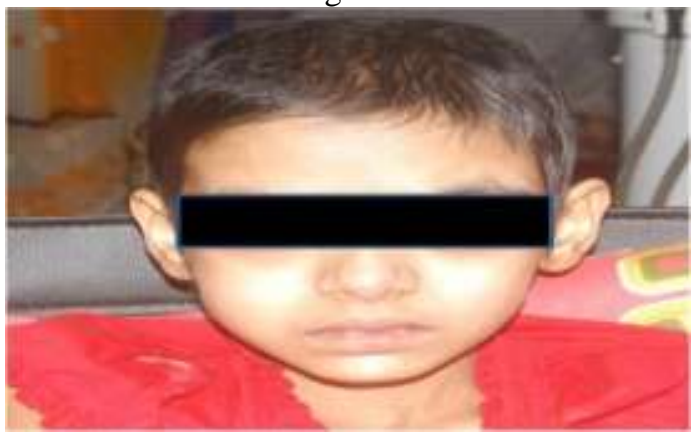

Fig. 1. A gross facial asymmetry with a well-circumscribed swelling present on the right posterior mandible. 


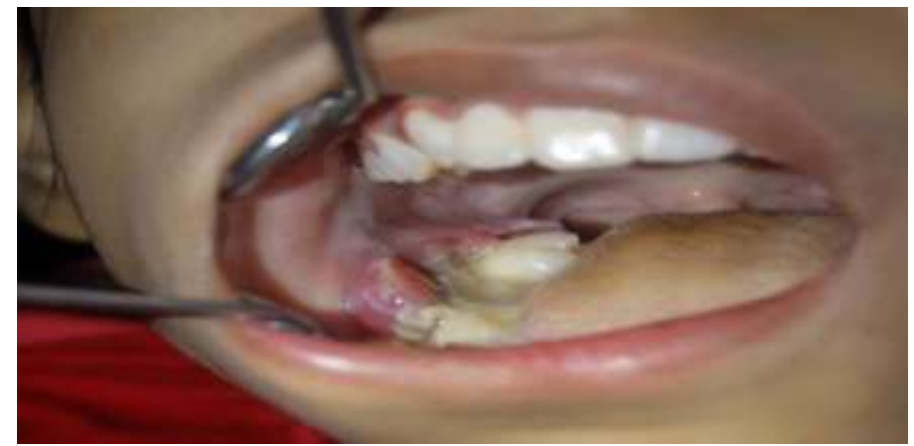

Fig. 2. Clinical image showing swelling in right posterior mandibular region.

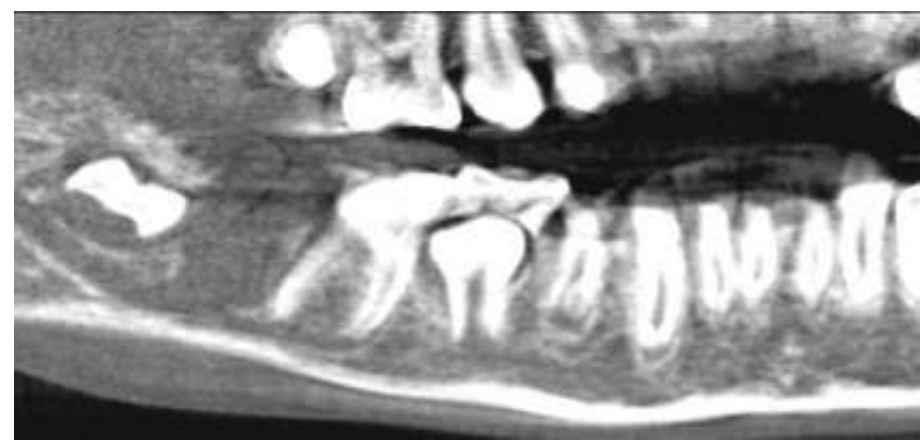

Fig.3. CBCT scan
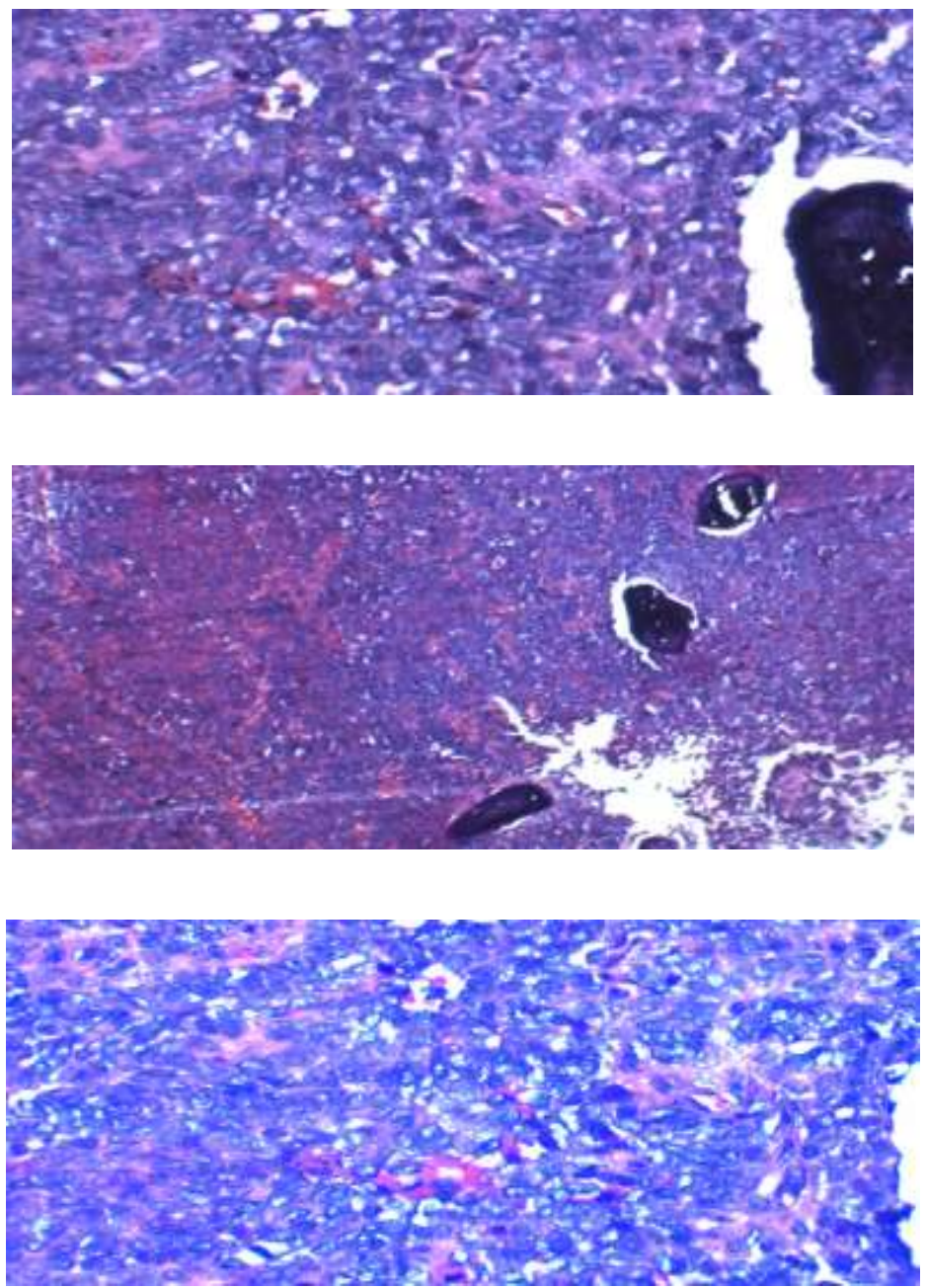

Fig.4.Histological view 